\title{
Evaluation and Analysis of Competitiveness of Regional Higher Education in China Based on Individual Advantage Characteristic*
}

\author{
Xin Wen ${ }^{1}$ \\ Shenyang University of \\ Technology
}

\author{
Yan'na Yin ${ }^{2}$ \\ Shenyang University of \\ Technology
}

\author{
Jian $\mathrm{Xu}^{3}$ \\ Shenyang University of \\ Technology
}

\begin{abstract}
Objective recognition of higher education development status and competitiveness is an important prerequisite and foundation for the transformation and development of regional higher education. At present, the identification and analysis methods for solving this problem cannot get rid of the subjective intention of reviewers or managers completely, and still adopt a unified evaluation standard. This makes the credibility of the results not high, resulting in not ideal implementation of follow-up policies and measures. In view of this, this paper proposes a method of individual advantage feature recognition to identify and evaluate regional higher competitiveness. This method is based on the description of the multi-indexes system of objects, and chooses the goal programming evaluation method to construct the mathematical model of individual superiority characteristic recognition, and explores the individual superiority characteristics of the regional higher education. This evaluation structure has intuitive interpretation and is easy to understand and accept.
\end{abstract}

\section{Keywords}

Regional Higher Education • Individual Advantage Characteristic • Competitiveness Evaluation

\footnotetext{
* Natural Science Foundation of China (71402104); Project of Science and Technology Bureau of Shenyang(F16-233-5-13); Project of Liaoning Provincial Federation Social Science Circles(20171slktyb-132); Project of Liaoning Planning Office of Philosophy and Social Science (L16BJY036).

${ }^{1}$ Correspondence to: School of Management, Shenyang University of Technology, 110870, China. Email: wenxin9901@126.com

2 School of Management, Shenyang University of Technology, 110870, China. Email: 64151517@qq.com

${ }^{3}$ School of Management, Shenyang University of Technology, 110870, China. Email: 13430739@qq.com
} 
As a key core factor affecting the development level and potential of a region or a country, the competitiveness of higher education is mainly embodied in its outstanding ability and relative advantages in the level of development and the effectiveness of production. This requires that the competitiveness evaluation of higher education accurately identify the development status and advantageous features of higher education in all regions of the state from a variety of indicators, which is conducive to making scientific decisions ${ }^{[2]}$ to promote and enhance the development of regional higher education. In essence, as an important part of regional competitiveness, it not only subordinate to the subsystem of regional economic and social system, but also a complex system itself (Wang Fang \& Sun, 2012). This makes the index elements that reflect the level and state of higher education competition also constitute a complex system. These indicators exist in different states and are in different dimensions and levels. Therefore, the effective identification and analysis of the advantages of regional higher education competitiveness has become a technical problem in the field of higher education competitiveness. The research on the competitiveness of higher education shifts from focusing on the relationship between regional higher education competitiveness and regional economic development to paying attention to the nature of regional higher education competitiveness. The former mainly reveals the mutual interdependence, mutual influence and mutual restriction between higher education and regional economic development (Zhang, 2003; Li, 2005; Wang \& Wang, 2006; Ma, 2007; Zhang, 2008; Zhou, 2011; Wang Wei \& Guo, 2015). In recent years, most scholars pay more attention to the latter, taking the competitiveness of higher education as the breakthrough point. For example, Zhao (2008), Si (2008), Zhang (2011), Xu (2013), Wang et al., (2016) studied the competitiveness of regional higher education, and then put forward corresponding suggestions and countermeasures for the development of regional higher education. In the aspect of analysis and evaluation methods, linear regression method, data envelopment analysis method (Data, Envelopment, Analysis, DEA) and the factor clustering and variance analysis and other means of quantitative or qualitative analysis of related data is adopted. These methods can be used to sort and analyze the competitiveness of regional higher education from different perspectives, which has certain reference significance for decision-makers and relevant managers. However, in the process of evaluation, they failed to shake off the idea of "unification". That is to say, in terms of index weight, the subjective color is heavy, which cannot effectively and comprehensively highlight the advantages of regional higher education competitiveness. This paper introduces the theory of competitive advantage analysis, which can effectively identify the advantages and characteristics of the object. Therefore, the evaluation of individual competitive advantages of regional higher education competitiveness in China can provide effective decision-making support for the relevant departments of education management.

\section{Identification method of individual advantage characteristic of regional higher education competitiveness}

\section{The identification of individual advantageous features in Regional Higher Education}

The so-called individual advantage characteristic refers that for an object being evaluated, if the evaluation results of the object under certain index weight allocation scheme are better than the evaluation results under 
any other index weight, then it is called that this object has individual advantageous features under this weight [17].

The analysis of the individual advantageous features of regional higher education competitiveness is that each region chooses its own individual advantageous characteristic weight from its own point of view, and then evaluates the competitiveness of higher education in all regions. Its purpose is to reflect the individual characteristics and relative advantages of the evaluation area itself. Since the process of gaining the weight of individual advantage does not require any human intervention, the method of democratic evaluation based on the analysis of individual advantage characteristics is an objective evaluation method (Zhao 2012).

1)The identification model of individual advantageous characteristics

Aiming at the evaluation of $\mathrm{n}$ objects withm evaluation indexes, the basic idea of individual advantage feature recognition model is as follows: In the sense of certain distance, from the point of view which is most favorable for the ith object being evaluated, the weight coefficient $\overrightarrow{\omega_{l \jmath}}$ is given to each index $\overrightarrow{x_{l}}=$ $\left(x_{i 1}, x_{i 2}, \ldots x_{i m}\right)^{\tau}(i=1,2, \ldots . n)$ describing the evaluated object. Then, the structure of the weight coefficient vector can reflect the individual advantage characteristic of the ith evaluation object.

Based on this, the goal programming model is constructed as follows:

$$
\begin{aligned}
& \operatorname{mind}_{w}\left(\bar{x}_{i}, \bar{x}^{*}\right)=\left(\sum_{j=1}^{m} w_{i j}^{2}\left|x_{j}^{*}-x_{i j}\right|^{2}\right)^{\frac{1}{2}} \\
& \text { s.t. } \sum_{j=1}^{m} w_{i j}=1 \\
& w_{i j} \geq 0 \quad i=1,2, \cdots n, j=1,2, \cdots m
\end{aligned}
$$

Where $\vec{x}^{*}=\left(x_{1}^{*}, x_{2}^{*}, \ldots x_{m}^{*}\right)^{\tau}$ represents the ideal outcome of various evaluation indicators. $\mathrm{d}_{\mathrm{i}}$ is the 2-norm distances of the ith object being evaluated $\overrightarrow{x_{l}}$ and the ideal point $\vec{x}^{*}$. The smaller $\mathrm{d}_{\mathrm{i}}$ is, the closer it isto the ideal point, and the better the ranking of the object $i$ being evaluated is.

The individual advantageous features of model (1) are mainly embodied in that: for the evaluated object i, the weight coefficient $\omega_{i j}^{*}$ is determined from the perspective that is most favorable to $i$. It can be seen that the weight coefficients of individual advantage characteristic of different objects must be different. At the same time, the optimal solution $\omega_{i j}^{*}$ of model (1) is not confirmed artificially. Therefore, the individual advantage characteristics identified by this model are objective.

2)Evaluation and analysis of individual advantage characteristics

By using model (1), ngroups of weight coefficient of individual advantage characteristics can be obtained for $\mathrm{n}$ objects being evaluated. Then, $\mathrm{n}$ evaluation results can be obtained from evaluating the $\mathrm{n}$ objects (also includes the evaluation on themselves) according to each group of weight (that is, from the perspective of each object to be evaluated). According to this, the individual advantage characteristic of each evaluation object can be evaluated and analyzed. 


$$
\begin{aligned}
& d_{i k}\left(\vec{x}_{k}, \vec{x}^{*}\right)=\sqrt{\left(\sum_{j=m}^{m}\left(w_{i j}\right)^{2}\left(x_{j}^{*}-x_{k j}\right)^{2}\right.} \\
& k=1,2,3 \ldots n
\end{aligned}
$$

Where, $d_{i k}$ is the distance between the evaluated object $k$ and the ideal ending, based on the individual advantage features of the target $i$. Because the smaller the value of formula (2) is, the better, the results are arranged in an ascending order. And in terms of the performance of individual advantage characteristics, according to the $80 / 20$ efficiency rule, it can be specified that through the ascending arrangement of calculation results of formula (2), if the examined object is in the top 5\%, the object who has been evaluated has excellent individual performance. If it is in the top $20 \%$, it is recognized as qualified. Others are viewed as unqualified or lack mainstream individuality.

3) Democratic evaluation based on the analysis of individual characteristics

Through formula (2), we can get the evaluation results of each object being assessed of all the objects, and collect the opinions of each object being assessed to realize the democratization of evaluation opinions. Therefore, the result of democratic evaluation of the individual advantage characteristic of evaluated object K:

$$
D_{k}=\frac{1}{n} \sum_{i=1}^{n} d_{i k}\left(\vec{x}_{k}, \vec{x}^{*}\right)=\frac{1}{n} \sum_{i=1}^{n} \sqrt{\left(\sum_{j=m}^{m}\left(w_{i j}\right)^{2}\left(x_{j}^{*}-x_{k j}\right)^{2}\right.}
$$

$$
k=1,2,3 \ldots n
$$

$D_{k}$ is arranged in an ascending and complementary order, and then the ranking of democratic evaluation of n evaluation objects are obtained.

\section{Identification and evaluation of individual advantage characteristics of regional higher education competitiveness}

\section{Evaluation index system of regional higher education competitiveness}

This paper uses 31 provinces in mainland China, including 22 provinces, 4 municipalities and 5 autonomous regions as evaluation samples. The evaluation index system draws on the research results of Zhang (2011), and selects 28 specific evaluation indexes according to the actual situation, as shown in Tab. 1.

\section{Data acquisition and data processing}

In this paper, the data of higher education in 31 regions of China in 2014 are analyzed which derived from the 2015 "China Statistical Yearbook", "Educational Statistics Yearbook of China", "China Statistical Yearbook of Science and Technology", "China Educational Finance Statistical Yearbook", portal website of theMinistry of Education of China, Website of Natural Science Foundation of China, and so on. Part of the data is figured out through calculating the data provided by statistical yearbook or authoritative website, striving to achieve consistent caliber in data collection. Giventhat the dimension of each index is different, it is necessary 
to standardize the raw data. Because the evaluation indexes here are very large indicators, the following formula is used to standardize the data:

$$
\begin{array}{r}
\hat{x}=\frac{x_{i j}-\min _{j}}{\max _{j}-\min _{j}} \\
i=1,2, \ldots n j=1,2, \ldots n
\end{array}
$$

Here, $\hat{x}_{i j}$ represents the numerical value after the normalization of the $j$ th index of the $i$ region. $x_{i j}$ represents the original data of the $j$ th index of the $i$ region. $\operatorname{Min}_{j}$ represents the minimum value of the $j$ th index. $\operatorname{Max}_{j}$ represents the maximum value of the $j$ th index. Through such index processing, the influence of dimension of different indexes is eliminated, and the standardized data is between $0-1$.

Table 1

\begin{tabular}{|c|c|c|}
\hline First-grade Index & $\begin{array}{l}\text { Second-grade } \\
\text { Index }\end{array}$ & Third-grade Index \\
\hline \multirow{23}{*}{$\begin{array}{l}\text { Educational } \\
\text { resources }\end{array}$} & \multirow{7}{*}{ Education scale } & $\begin{array}{l}\text { X1 the number of ordinary college students per million people } \\
\text { (person) }\end{array}$ \\
\hline & & $\mathrm{X} 2$ the number of doctoral students per million people (person) \\
\hline & & $\mathrm{X} 3$ the number of master students per million people (person) \\
\hline & & X4 the number of institutions of higher learning (institute) \\
\hline & & X5 the number of projects " 211 " and " 985 " universities (institute) \\
\hline & & X6 the number of postgraduate training institutions \\
\hline & & $\begin{array}{l}\mathrm{X} 7 \text { the proportion of full-time teachers in teaching and } \\
\text { administrative staff }\end{array}$ \\
\hline & \multirow{3}{*}{$\begin{array}{l}\text { Faculty } \\
\text { strength }\end{array}$} & X8 Academicians number \\
\hline & & $\begin{array}{l}\text { X9 the percentage of full-time teachers with the title of vice senior } \\
\text { or above }\end{array}$ \\
\hline & & X10 the proportion of full-time teachers with doctor's degree \\
\hline & \multirow{7}{*}{ Basic resources } & X11 Faculty-to-student ratios \\
\hline & & X12 School building area per student \\
\hline & & X13 Fixed assets per student \\
\hline & & $\begin{array}{l}\text { X14 the number of ordinary books and e-books per student } \\
\text { (volume) }\end{array}$ \\
\hline & & $\begin{array}{l}\text { X15 the value of teaching and laboratory equipment per student } \\
\text { (million yuan) }\end{array}$ \\
\hline & & X16 the number of national talent training bases \\
\hline & & $\begin{array}{l}\text { X17 Project number of National Natural Science Foundation of } \\
\text { China }\end{array}$ \\
\hline & & X18 Education expenditure in regional budget per student (yuan) \\
\hline & \multirow{5}{*}{ Funds input } & $\begin{array}{l}\text { X19 the ratio of educational expenditure budget per student in the } \\
\text { region to that of the whole nation }\end{array}$ \\
\hline & & X20 Budgetary public funds for education per student (yuan) \\
\hline & & $\begin{array}{l}\text { X } 21 \text { the ratio of budgetary public funds for education per student } \\
\text { in the region to that of the whole nation }\end{array}$ \\
\hline & & X22 R\&D funds (million yuan) \\
\hline & & $\begin{array}{l}\text { X23 the proportion of } R \& D \text { funds in universities in regional } R \& D \\
\text { funds }\end{array}$ \\
\hline \multirow{6}{*}{$\begin{array}{l}\text { Educational } \\
\text { gains }\end{array}$} & \multirow{4}{*}{$\begin{array}{l}\text { Personnel } \\
\text { training }\end{array}$} & X24 Graduation rate \\
\hline & & X25 Employment rate \\
\hline & & X26 Degree granting rate \\
\hline & & X27 the number of Excellent Doctoral Dissertations in China \\
\hline & Scientific & $\mathrm{X} 28$ the number of papers indexed by three major searches \\
\hline & research & $\mathrm{X} 29$ number of R\&D projects \\
\hline
\end{tabular}

Identification index system of individual characteristics of regional higher education competitiveness 


\section{The solution and evaluation process of individual advantage characteristics}

1) Solving the individual advantage characteristics

The individual advantage characteristic weight can be figured out through calculating the standardized data in each region by model (1), and 31 groups of weight vectors are obtained.

2) Evaluating the individual advantage characteristics

In each group of weights vector, the evaluation results of 31 regions are calculated according to formula (2), a total of $31 \times 31=961$ results. Rank the results of each column in ascending order, and the ranking of individual advantage characteristics in different regions is obtained.

3) Democratic evaluation based on individual advantage characteristics

The democratic evaluation value of individual advantage characteristics in each region is calculated by formula (3). Democratic evaluation values are ranked in an ascending order. The ranking of democratic evaluation of higher education competitiveness based on individual advantage characteristics in 31 regions of China is shown in Tab. 2.

Table 2

Regional Higher Education Competitiveness Evaluation Score and Ranking Table

\begin{tabular}{cccc}
\hline Order number & Region & Order number & Region \\
\hline 1 & Shaanxi & 16 & Zhejaing \\
2 & Chongqing & 17 & Tianjin \\
3 & Sichuan & 18 & Xinjiang \\
4 & Hubei & 19 & Jiangxi \\
5 & Henan & 20 & Guizhou \\
6 & Guangdong & 21 & Ningxia \\
7 & Tibet & 22 & Hainan \\
8 & Liaoning & 23 & Guangxi \\
9 & Anhui & 24 & Heilongjiang \\
10 & Fujian & 25 & Qinghai \\
11 & Shandong & 26 & Shanghai \\
12 & Yunnan & 27 & Jilin \\
13 & Hunan & 28 & Hebei \\
14 & Gansu & 29 & Beijing \\
15 & Jiangsu & 30 & Inner Mongolia \\
& & 31 & Shanxi \\
\hline
\end{tabular}

4) According to the formula (3), the decision units are arranged in an ascending order. If the performance of the decision unit $i$ under its value parameter structure is in top 5\%, it is deemed that its individual advantage features are prominent, and that its comparative advantage is obvious. If it is in top $20 \%$, it has certain individual advantage characteristics, and its comparative advantage is general. Otherwise, it is deemed as lacking individual advantages, and there is no comparative advantage. 


\section{Analysis of individual advantage characteristics of regional higher education competitiveness in China}

\section{Identification of individual advantage characteristics}

Through the calculation of model (1), the weight coefficients reflecting the advantage characteristics in each region can be obtained. The larger the value of the weight is, the more obvious the individual advantage characteristics represented by the index in this region is. Taking Shanghai city as an example, the weighted coefficient of its advantage characteristics is $\omega$, which equals to $(0.0077$ ,0.0047,0.008,0.006,0.0053,0.0064,0.0038,0.0039,0.0127,0.0323,0.0042,0.008,0.0218,0.0194,0.0135,0.0098,0 $.0083,0.0497,0.2912,0.0523,0.0752,0.0071,0.0051,0.0089,0.0171,0.2912,0.0031$, and 0.0043). From the data, it can be seen that the advantage characteristics of higher education competitiveness in Shanghai are mainly embodied in five aspects: $\mathrm{X}_{10}, \mathrm{X}_{13}, \mathrm{X}_{18}, \mathrm{X}_{19}$ and $\mathrm{X}_{26}$, and it is the same in other areas. By analyzing the weight coefficient, we can find that when a region has a significant advantage in a certain or some indicators, the weight value of these indicators is relatively large. This shows that the individual advantage characteristics of higher education competitiveness in each region can be fully revealed if the weight index is confirmed from the perspective that is the most favorable to the region.

\section{Analysis of individual advantage characteristics}

Through the calculation using model (2), the evaluation value of higher education competitiveness in other regions can be obtained from the perspective of each region separately. Then we can get rankings of higher education competitiveness in each region from the perspective of each region. In accordance with the definition of individual advantage characteristics, and from the perspective of the evaluated region, the top 2 in the evaluated areas performed excellently, and the top 6 are viewed as qualified, while the rest are deemed as lacking individual advantages. Judging from the ranking of personality evaluation, the 31 provinces and cities generally have certain individual advantage characteristics. According to the analysis of the individual advantage characteristics ranking, we can see that except such six regions as Hebei, Shanxi, Inner Mongolia, Jilin, Hunan and Guangxi, the competitiveness of higher education in other 25 regions has obvious advantages. The competitiveness of higher education in Jilin and Hunan has certain individual advantage characteristics, which shows that there are still areas better than these regions even through making evaluations from the perspective that is the most favorable to these regions. And those better areas become the "examples" to be learned by these four regions because the evaluation results are obtained from the perspective that is the most favorable to them. Therefore, compared with the "uniform weight standard" evaluation methods, these areas are more likely to accept the results of this evaluation, and actively analyze their own shortcomings contrasting the "example" analysis of their deficiencies, thus mobilizing their initiative to improve the competitiveness of higher education. The competitiveness of higher education in Hebei, Inner Mongolia and Guangxi lacks individual advantage characteristics. For this kind of region, they should focus on the analysis of the reasons behind, and then reenact the development goals. It is necessary to analyze the external environment seriously, boldly innovate, and actively adjust the internal advantageous resources. At the same time, they should choose 
the areas with outstanding individual advantage characteristics as learning benchmarks, so as to improve their own competitiveness of higher education.

\section{Democratic Evaluation Based on the Characteristics of Individual Advantage}

The ranking results of democratic evaluation of each region can be obtained through the calculation of model (3). Whether the assessment was carried out from the perspective that is most conducive to each region or it is the democratic evaluation based on the characteristics of individual advantage, the regions with strong higher education competitiveness in Shaanxi and Chongqing regions always come out top. They are the excellent ones recognized by the public. Shanxi and Inner Mongolia are the commonly recognized areas with relatively low higher education competitiveness among the groups that participate in the evaluation. Since the democratic evaluation is carried out based on the premise of not violating the public interest and highlighting the advantage of each object, obviously, the assessment results reflect the individuation and democracy of the assessment, which are easy to be accepted by the public.

\section{Overall Characteristics and Analysis of the Competitiveness of Regional Higher Education in China}

According to the rules of division of the administrative region in China, it is divided into six sections: North China, Northeast China, Eastern China, South Central China, Southwest China and Northwest China. The comprehensive calculation results show that the regional higher education in China is featured by unbalanced overall distribution and distinct regional disparity.

1) Analysis of the Competitiveness of Higher Education in North China

North China covers Beijing, Tianjin, Hebei, Shanxi and Inner Mongolia. As can be seen from the individualized ranking, the higher education competitiveness of Beijing and Tianjin are in the top two, with significant individual advantages. The higher education competitiveness of other three regions is relatively low in the ranking and lacks individual advantage. From the perspective of regional economic pattern, the distribution of higher education competitiveness is related to, but not completely consistent with the situation of regional economic development. Gross regional production is the final outcome of the production activities of all resident units in the region in a period of time and equals to the sum of the added value of every industry. Therefore, according to the meaning and characteristics of gross regional production, it is regarded as a reference index. According to the ranking of regional GDP of the past five years released by the National Bureau of Statistics, Shanxi ranked around the 20th among the 31 provinces and cities, showing a slightly declining trend. The speed of development of regional economy was much lower than that of higher education. Similarly, the regional economy in Inner Mongolia was developing at a rate slightly slower than the development rate of its higher education, suggesting the higher education was not compatible with its regional economic development and that the advantages of higher education had not been prominently reflected in regional economic growth. Hebei province ranked the sixth among the 31 provinces and cities by gross regional production. Its regional economy development was sound, and higher education competitiveness ranking was 
relatively high, indicating that its regional economy development speed was consistent with that of higher education development and that the higher education in this province was in harmony with its economic development. Beijing ranked low in the democratic evaluation on higher education competitiveness, and its gross regional production ranked in the middle position for five consecutive years, signifying its regional economic development speed was relatively uncoordinated with the development speed of education. Tianjin ranked the 20th for five consecutive years by gross regional production. Its regional economic development is relatively superior to its higher education competitiveness and the development of economy and higher education is in harmony.

\section{2) Analysis of the Competitiveness of Higher Education in Northeast China}

The Northeast region covers Liaoning, Jilin and Heilongjiang. Liaoning and Heilongjiang have significant individual advantages, while Jilin area has general advantageous features, and its performance is basically qualified. According to the development practice of Liaoning province, the development of higher education in Liaoning province is slightly slower than that of the economy development, which can be seen from the rank of Liaoning area in Table 4. Combining Table 3 and 4, it can be seen that the speed of economic development in Heilongjiang province is higher than that of the higher education competitiveness and there is weak interaction between the higher education and economic and social development. The development speed of economy in Jilin region is lower than that of higher education, revealing inconsistent development. The interaction between higher education and social and economic development has not been reflected.

3) Analysis of the Competitiveness of Higher Education in Eastern China

Eastern China includes seven provinces and cities, namely Shanghai, Jiangsu, Zhejiang, Anhui, Fujian, Jiangxi and Shandong. Seen from the ranking of higher education competitiveness based on individual advantageous features in Eastern China, each province boasts prominent individual advantageous features. Eastern China has been in the leading position in terms of economic development throughout the country. In the last five years of ranking of gross regional production, Jiangsu, Shandong and Zhejiang was in the top position for five consecutive years. The economic development speed of these three regions is significantly higher than that of their higher education. The interaction between education and economic development has not been reflected. Anhui ranked in the middle position among 31 provinces and regions in terms of gross regional production for five consecutive years. Its regional economic development rate is higher than that of higher education, but its gross regional production ranking has not changed. The discordance between the higher education competitiveness and regional economic development is rather prominent. The ranking of Shanghai by gross regional production was stable for five consecutive years, which is in the middle. But its higher education competitiveness is in the middle and lower level. The economic development speed is slightly higher than the development speed of its higher education. Fujian province ranked in top position among the 31 provinces and cities by gross regional production. Although its economic development speed is higher than that of its higher education, there is interaction between the two. The GDP of Jiangxi province was at a moderate and lower level for five consecutive years and its higher education competitiveness has risen from the previous middle and lower level to the medium level. The development speed of education in Jiangxi region is slightly 
higher than that of its regional economy, and the interaction between them is not obvious. Its economic development is not heavily dependent on the higher education.

4) Analysis of the Competitiveness of Higher Education in South Central China

The South-Central China includes Henan, Hubei, Hunan, Guangdong, Guangxi Zhuang Autonomous Region and Hainan. Henan, Hubei and Guangdong have distinct individual advantages and features. Hunan boasts general advantageous features. Guangxi does not have distinct individual advantageous features. According to the economic development ranking shown in Table 3 and Table 4, the economic development in Henan province matches the development level of its higher education. The standing list shows that in the past five consecutive years, the higher education competitiveness of Hubei province was declining year by year and had fallen to the lower ranking, while its gross regional production went up year by year and rose to the ninth position, suggesting that its regional economic development speed is faster than that of the higher education. The development speed of higher education competitiveness of Hunan is slightly higher than that of its regional economy. The change of ranks of the two shows that there is no obvious interaction between the two. The higher education competitiveness of Guangdong ranked in the middle position, while its gross regional production had been outstanding in these five years. Its economic development speed is much higher than its higher education development speed, showing the coordination between the two is bad. The higher education competitiveness of Guangxi Zhuang Autonomous Region lacks individual advantageous feature and ranked low in agent democratic evaluation. Therefore, it can be inferred that the higher education competitiveness of Guangxi Zhuang Autonomous Region obviously lags behind other regions, which is related to its economic development level. The interaction between the two is not obvious.

\section{5) Analysis of the Competitiveness of Higher Education in Southwest China}

The Southwest China includes Chongqing, Sichuan, Guizhou, Yunnan, and Xizang Autonomous Region. The higher education competitiveness of these five regions all have distinct individual advantages and features. It can be seen from the ranking of Chongqing's gross regional production that the development speed of its higher education is slightly higher than that of its economy. However, the interaction between the two appears. The competitiveness of higher education in Sichuan region has been in a favorable position all over the country, with significant individual advantage. Its gross regional production ranked the eighth position for five consecutive years. The development speed of higher education in Sichuan province is harmonious with its economy development speed and there is obvious interaction between the two. The ranking of Guizhou's gross regional production is also in the middle and lower position. It can be seen that its higher education development is consistent with its economic development. The economic development speed of Yunnan is faster than that of its higher education and the development level of the two is fairly harmonious. The higher education in Xizang was developing slightly faster than its economy, but the development level of the two is low and is inconsistent.

6) Analysis of the Competitiveness of Higher Education in Northwest China

The Northwest China includes Shaanxi, Gansu, Qinghai, Ningxia Hui Autonomous Region and Xinjiang Uygur Autonomous Region. Judging from the gross regional production and Table 3 and Table 4, the economy in Shaanxi province was developing faster than its higher education. The development of the two is 
inharmonious and their interaction is not revealed. The development speed of the higher education in Gansu is much higher than that of its economy, suggesting that the development level of the two is extremely incongruous. The development speed of higher education in Qinghai region is faster than that of its economy, and the development of the two is inharmonious. The development speed of higher education in Ningxia Hui Autonomous Region is much faster than that of its economy, revealing extreme inconsistency between the two and the interaction between the two was not revealed. The development speed of higher education in Xinjiang is much faster than that of its economy, signifying extreme inconsistency between the two and the interaction between the two was weak.

Reviewing the development of regional economy and higher education competitiveness in 31 provinces and cities, the development speed of economy in Tianjin, Liaoning, Heilongjiang, Jiangsu, Shandong, Zhejiang, Anhui, Shanghai, Fujian, Henan, Hubei, Guangdong, Shaanxi and Xizang is faster than that of their higher education, suggesting that the interaction between social economy and higher education has not been fully reflected and that the requirement of economic growth on talent and technology is low. It is still at the stage of extensive growth. However, with the adjustment of economic growth model and economic structure, the economic growth is more and more dependent on the higher education and has a higher and higher demand for talents and technology. There will be a substantial improvement in the competitiveness of higher education. The higher education development in Hebei, Beijing and Sichuan is more harmonious with their regional economic development and the interaction between social economy and higher education has been reflected.

The economic growth and its requirement on talents and technology are becoming harmonious. The higher education development speed in other provinces and cities is faster than the development of their regional economy. These provinces and cities shall also pay close attention to the contribution rate of higher education to social and scientific progress and talent output while developing higher education.

\section{Policies and suggestions on the enhancement of higher education competitiveness based on individual advantageous features}

First, national macro support is a strong guarantee. The country's educational policy needs to be adjusted at this stage, and it should shift its focus from the nine regions that have been given priority to development to less developed areas. When providing financial support or making policy options, the government shall get the root cause, make the direction definite, and carry out necessary supervision and guidance, thus promoting the higher education development in the undeveloped area in a targeted, planned and orderly way. The state should support the construction of a certain number of colleges and universities with global influence to attract more highquality teachers and students.

Second, regional development is the key factor. First, it is important for the undeveloped areas to recognize the importance of education and higher education. Secondly, they should actively find out their gap with other regions, position themselves accurately, and develop practical and feasible route strategy for own development. What needs to be pointed out is that in an era when the state is attaching more and more importance to the development of backward regions such as central and western regions, these regions should be able to control 
and utilize resources rationally and put an end to the phenomenon of "large and all inclusive" universities. Previous research has shown that there are many regions that are not well developed in some aspects, thus becoming the bottleneck and hindrance of the development of higher education in the region. For instance, the hardware facilities are complete or the scientific research funds are abundant, but there is no high-quality human capital (including teachers and student pool), or corresponding scientific research output are lacking, etc. Take Jiangxi province as an example, education resources in this region are abundant, and the advantageous features of other indicators are not obvious, thus affecting the overall score. It shows that some problems in the process of education affect the scientific research output and education efficiency. Therefore, colleges and universities in each region shall constantly find their own advantages and disadvantages and adjust their development strategies in a timely manner to achieve balanced and sustainable development.

Third, the mutual assistance and communication between regions is a favorable condition. The polarization of higher education strength is very serious, and the development level of higher education is very weak in a large part area of the country. According to the theory of "getting rich first and getting rich together", it is necessary for the regions with relatively developed higher education to promote the areas with relatively backward higher education, and finally achieve the common prosperity and balanced development of higher education. After all, national resources are limited and it is difficult for a university to change the current pattern by relying solely on its own strength. Regions with relatively developed higher education boast rich education resources, if they can share the resources with regions having relatively backward higher education, the education resources can be fully utilized and optimized, and the higher education in backward regions are promoted within a short period of time, meanwhile, the regions with relatively sound higher education play a model and positive role in promoting the balanced and harmonious development of the higher education nationwide. Therefore, continuously strengthening the degree of mutual aid between area and expanding regional communication range can yet be regarded as a kind of highly effective solution with good benefit, and is a choice that can effectively improve the current higher education pattern, having an effect of killing three birds with one stone.

\section{Conclusion}

In this paper, a new evaluation method is used to evaluate the competitiveness of higher education in 31 provinces and cities in the past five years. According to the analysis of the individual advantageous features and democratic evaluation, the ranking of the competitiveness of higher education in 31 provinces and cities was carried out, aiming to evaluate each object from the perspective that is the most favorable to the object.

It is concluded through analysis that the ranking of competitiveness of higher education in economically powerful provinces is not necessarily good, and the ranking of competitiveness of higher education in economically backward region is not necessarily at the bottom. The reason is that our country's higher education resources have not been optimized and a part of the education resources have not been fully utilized. Therefore, the competitiveness of higher education in one region is the result of the comprehensive function of education resources. The resources utilization efficiency will be lowered if other factors are neglected and only the 
resources input is emphasized. Only when China's higher education resources are distributed evenly in all provinces in China, can the overall development of higher education be promoted.

\section{References}

Fei, X. T. (1997). Life and changes of peasants in jiang village, Lanzhou: Dunhuang literature and art publishing house, 322 .

Li, X. F. (2005). The sustainable development of higher education and regional economy. Journal of Hulunbeier College, 3, 42-44.

Liu, Y. (2012). How to look at the China model of the development of education. Jiangsu High Education, (1), 14-17. http://dx.doi.org/10.13236/j.cnki.jshe.2012.01.071.

Ma, W. L. (2007). Research on the benign interaction between higher education and regional economic development. Business perspective, (11), 207-208.

Si, L. B., Zhao, X. D., \& Qie, S. J. (2008). Research on the evaluation and countermeasures of higher education competitiveness in Hebei province. National Education School of Administration, 8, 31-38.

Wang, Q. G. (2016). Evaluation and countermeasure of the competitiveness of education in China's region, Laboratory Research and Exploration, 2, 269-272.

Wang, S. F., \& Wang, Y. X. (2006). Theoretical discussion on the relationship between education and regional economic development. Journal of Beijing University of Commerce and Industry, (social science edition), 3, 89-92.

Wang, S., Fang, Y. \& Sun, Y. Z. (2012). Higher education competitiveness: Model, index and international comparison. Education research, (7), 122-129

Wang, Z. C. Qi, \& W. Guo, J. J. (2015). Research on the coordination degree of education and regional economic development in China., Degree and Postgraduate Education, 4, 66-71, http://dx.doi.org/10.16750/j.adge.2015.04.015

Xu, T. W., Cai, W. H., \& Wang, Y. C. (2013). Yunnan higher education development level of evaluation, based on the research on higher education competitiveness evaluation index system. Journal of Yunnan Normal University (philosophy and social sciences edition), 45(4), 150-156.

Zhang, J. (2003). Reflections on the establishment of a benign interactive relationship between education and regional economy -- a number of problems in regional economic development. Journal of Hubei School of Economics, 5, 108-122.

Zhang, L. F. (2008). Empirical relationship between higher education and economic growth in hebei province. Technical Economy and Management Research, 4, 105-107.

Zhang, W. \& Xu, G. Y. (2015). Evaluation results and analysis of education competitiveness in some developed regions. Education, 12, 92-94

Zhang, X. P. Liu, Z. Q. Li, X. Y. Zhang, C. (2011). Empirical research on the competitiveness of higher education in Liaoning province. Modern Education Management, 5, 30-34.

Zhao, H. B. (2008). Research on the competitiveness of education in China region. National Education School of Administration, 8, 25-30.

Zhao, X. A. Theoretical method and application of competitive analysis, Shenyang: Science press. 
Wen, Yin, Xu / Evaluation and Analysis of Competitiveness of Regional Higher Education in China Based...

Zhou, H. L. (2011). Effects of higher education on economic growth taking Guangdong province as an example. Journal of south China university of technology (social sciences), 13(6), 89-92. 